\title{
GÉRARD COGEZ, Aimé Césaire
}

\section{Roberto Ferraroni}

\section{CpenEdition \\ Journals}

\section{Edizione digitale}

URL: https://journals.openedition.org/studifrancesi/23324

DOI: 10.4000/studifrancesi.23324

ISSN: 2421-5856

\section{Editore}

Rosenberg \& Sellier

\section{Edizione cartacea}

Data di pubblicazione: 1 avril 2020

Paginazione: 229

ISSN: 0039-2944

\section{Notizia bibliografica digitale}

Roberto Ferraroni, "GÉRARD Cogez, Aimé Césaire», Studi Francesi [Online], 190 (LXIV | I) | 2020, online dal 01 mai 2020, consultato il 03 août 2021. URL: http://journals.openedition.org/studifrancesi/23324 ; DOI: https://doi.org/10.4000/studifrancesi.23324

\section{Questo documento è stato generato automaticamente il 3 août 2021}

\section{(c) (†)}

Studi Francesi è distribuita con Licenza Creative Commons Attribuzione - Non commerciale - Non opere derivate 4.0 Internazionale. 


\title{
GÉRARD COGEZ, Aimé Césaire
}

\author{
Roberto Ferraroni
}

\section{NOTIZIA}

GÉRARD COGEZ, Aimé Césaire, Lausanne, Ides et Calendes, 2018, 125 pp.

1 Il saggio di Cogez, pubblicato per la collana «Le théâtre de», offre al lettore un interessante viaggio nel mondo delle opere teatrali di Aimé Césaire, il ben noto scrittore originario della Martinica e fondatore, con Léopold Sédar Senghor e LéonGontran Damas del movimento della Négritude, nato per rivendicare l'orgoglio della popolazione nera e per favorirne la rinascita dopo il lungo periodo di sottomissione del colonialismo. Dopo un capitolo iniziale che riassume i momenti più importanti della vita di Césaire e il suo rapporto con il teatro, inizia il vero e proprio viaggio nella sua produzione drammaturgica. Cogez decide di compierlo seguendo un ordine cronologico, a partire dalla sua prima tragedia, Et les chiens se taisaient, a cui viene dedicato il secondo capitolo. Nell'architettura del saggio il terzo capitolo rappresenta un'eccezione poiché l'autore approfondisce due opere non teatrali di Césaire: Discours sur le colonialisme, saggio apparso per la prima volta nel 1950, e Toussaint Louverture (1962), biografia del famoso rivoluzionario haitiano, che tanto interesse suscitava nell'autore martinicano. La digressione del capitolo, che si allontana momentaneamente dal teatro, è senza dubbio ben contestualizzata e strettamente legata al capitolo precedente: infatti, se da un lato il tema del colonialismo è da sempre così caro a Césaire che anche il suo teatro ne è pervaso, dall'altro il Rebelle protagonista di Et les chiens se taisaient è una figura chiaramente ispirata a Toussaint Louverture, così come il Christophe de La tragédie du roi Christophe, a cui è dedicato il quarto capitolo. Da questo punto in avanti, Cogez si concentra interamente sui drammi di Césaire.

2 Riuscire a "contenere" la sua opera teatrale in un così breve saggio è sicuramente complicato, ma Cogez riesce a farlo, dal punto di vista del contenuto, in maniera estremamente esaustiva. Da ogni pagina del saggio emerge in modo chiaro ed evidente che l'intera drammaturgia di Césaire è intrisa e pervasa dal suo fervore politico. 
Ognuna delle sue opere è legata indissolubilmente alla passione dell'autore per la causa della popolazione nera, troppo a lungo sottomessa e abusata dai colonizzatori bianchi. Dall'analisi approfondita di Cogez emerge l'evoluzione che le tematiche trattate hanno subito nel corso degli anni per passare poco a poco da moderate - ma nette - critiche al sistema del colonialismo a dirette invettive e aperti attacchi nei confronti dei paesi maggiormente sviluppati, responsabili dello sfruttamento delle popolazioni africane, come in Une saison au Congo, penultima opera ad essere analizzata. È già possibile osservare in quest'opera anche un altro aspetto dell'ideologia politica di Césaire che verrà poi portato all'estremo in Une tempête, a cui è dedicato il sesto capitolo: le responsabilità del colonialismo non sono da ricercare solo nei paesi oppressori, bensì anche in quei politici africani che hanno permesso - e permettono - ai "potenti" di dettar legge nel loro territorio. Se in Une saison questo è sussurrato a bassa voce dall'autore, in Une tempête viene urlato con forza: Césaire, che ha ricoperto anche cariche politiche importanti nella sua Martinica, non riesce a comprendere perché siano gli stessi martinicani a non volersi realmente ribellare agli oppressori. Con un po' di disincanto Aimé Césaire si allontana così dal teatro, che avrebbe potuto essere un propulsore attraverso cui i suoi connazionali avrebbero potuto capire chi fossero e trovare la forza per reagire a una condizione che per troppo tempo li aveva visti sottomessi ai paesi europei.

3 Se dal punto di vista dell'analisi delle tematiche presenti nel teatro di Césaire, la bontà del lavoro di Cogez è evidente, quello di cui si sente la mancanza in questo saggio è l'approfondimento degli aspetti stilistici - il linguaggio utilizzato dai personaggi, le tecniche di costruzione delle pièces, la loro struttura - delle sue opere.

4 A chiudere il saggio sono un'interessante cronologia delle rappresentazioni teatrali trattate e una ricca bibliografia. Nel complesso il volume è un'ottima prova per l'autore che propone al lettore uno studio molto interessante e ben dettagliato della materia trattata, riuscendo a trasmettere in maniera inequivocabile la passione e il sentimento di Césaire nello scrivere le sue pièces. 